\title{
PERFORMANCE EVALUTION AND EXERGY ANALYSES OF AN INTEGRATED SOLAR COMBINED CYCLE POWER PLANT
}

\author{
K. K. Matrawy \\ Department of Mechanical Engineering, Faculty of Engineering, \\ Assiut University, Egypt \\ Present address: Department of Mechanical Engineering, Faculty of \\ Engineering, $7^{\text {th }}$ October University P.O.Box 327, Misurata, Libya
}

(Received August 10, 2008 Accepted September 28, 2008)

The present study is aimed to develop an integrated solar combined cycle power plant in which steam generator gets its energy by recovering the wasted heat of a gas turbine unit. The plant included also a concentrating collector field to heat the water coming from condenser replacing the regenerative process in Rankine cycle. In such a way, the extracted steam used for regenerative cycle can be used in other applications such as, heating process, desalination,...etc (Co-generation cycle). Producing saturated steam and superheating process are taken place in steam generator via recovering the wasted heat accompanying the exhaust gases of the gas turbine. An auxiliary heater is used at lower or less solar radiation times.

A simulation mathematical model has been developed for each component of the plant and the components are matched together. This model is used to predict the temperatures, mass and heat transfer within the system under various operating and design conditions. The influence due to extracting a variable amount of steam for heating process is studied in the paper. The studied parameters included the contributions of the solar as well as the wasted energy with the products of the gas turbine. An exergy analyses for the main components of the plant are considered in the study. The final results showed that the solar energy can contribute by about 27 $\%$ from the total energy supplied to Rankine cycle whereas the energy recovery from the wasted energy of the gas turbine can contribute by about $64 \%$. The remaining part is covered by an auxiliary heater. The values of the efficiencies reached to about, $54 \%$ for the solar collector, $46 \%$ for the gas turbine, $43 \%$ for the utilization factor of the steam turbine and $45 \%$ for overall efficiency of the solar integrated combined cycle power plant. Also, the most exergy destruction in the plant occurred in the solar concentrator (about $33 \%$ of the incident radiation), and the combustion chamber of the gas cycle (about $39 \%$ of the input heat). Other components such as, compressor, gas turbine, steam turbine, and condenser, having an exergy destruction ranges from $1 \%$ up to $5 \%$ from the corresponding energy input to each component.

KEYWORDS: solar concentrating collector, Gas turbine, Steam turbine, Solar contribution, Exhaust gases contribution, Efficiency, Utilization factor 


\section{NOMENCLATURES}

Q heat (W)

FR heat removal factor

A area $\left(\mathrm{m}^{2}\right)$

$\mathrm{S}$ absorbed radiation $\left(\mathrm{W} / \mathrm{m}^{2}\right)$

F collector efficiency factor

$\mathrm{T}$ temperature (K)

Mw mass of water in solar loop, $(\mathrm{Kg} / \mathrm{s})$

M mass of extracted steam for process heating, $(\mathrm{Kg} / \mathrm{s})$

$\mathrm{Cp} \quad$ specific heat $(\mathrm{J} / \mathrm{Kg} . \mathrm{K})$

\section{D}

$\mathrm{h}_{\mathrm{fi}}$

$\mathrm{h}_{\mathrm{w}}$

$\mathrm{t}_{\mathrm{c}}$

$\mathrm{K}_{\mathrm{c}}$

$\mathrm{N}$

$\mathrm{R}$

$\mathrm{P}$

$\mathrm{h}$

\section{Symbols}

a aperture, ambient

$\mathrm{ab}$ absorber

aux. auxiliary

c cover, cold

$\mathrm{cw}$ cooling water

D.A dry air

f saturated liquid

fi fluid inlet

in diameter (m)

inside heat transfer coefficient $\left(\mathrm{W} / \mathrm{m}^{2} . \mathrm{K}\right)$

wind coefficient $\left(\mathrm{W} / \mathrm{m}^{2} \mathrm{~K}\right)$

glass cover thickness (m)

glass cover thermal conductivity (W/m.K)

number of concentrators

gas constant $(\mathrm{J} / \mathrm{Kg}$. K)

pressure $(\mathrm{Pa})$

enthalpy $(\mathrm{Kj} / \mathrm{Kg})$

$\begin{array}{ll}\mathrm{g} & \text { saturated vapor } \\ \mathrm{h} & \text { hot } \\ \mathrm{i} & \text { inner } \\ \mathrm{o} & \text { outer } \\ \text { sup } & \text { superheated } \\ \text { sat } & \text { saturated } \\ \mathrm{u} & \text { useful } \\ \mathrm{r} & \text { relative }\end{array}$

\section{INTRODUCTION}

Conventional combined cycle power plants are a very attractive configuration in recent years. Gas turbine cycle typically operates at considerably higher temperatures than steam cycle where the maximum temperature in steam turbine is nearly $620{ }^{\circ} \mathrm{C}$ while the corresponding value is over $1150{ }^{\circ} \mathrm{C}$ in gas turbine [1]. Because of the higher average temperature at which heat is supplied in gas turbine, its efficiency is greater than the steam cycle. On the other hand, the gas turbine has some disadvantage where the exhaust gases leave the gas turbine at high temperatures (about $500{ }^{\circ} \mathrm{C}$ ) which erases any potential gains in the thermal efficiency. Thus, an energy recovery from the heat of the exhaust gases will enhance the overall efficiency via combining gas cycle by steam cycle. This can be occurred by transferring the wasted heat to the steam by using steam generator that serves as the boiler resulting a combined gas-steam cycle. The combined cycle power plant having widespread commercial applications due to [2]:

1. High cycle thermal efficiency or low heat rate.

2. Reduction in need for cooling water since only the steam turbine of the cycle needs cooling water.

3. Ability to be built in stages. The gas turbine can be installed initially and operate as a simple cycle gas turbine. At a later date, the steam turbine can be added and then operated as a combined cycle power plant. 
4. Ability to operate the gas turbine with the steam turbine idle if a diverter valve was installed so that the gas turbine exhaust gas can bypass the heat recovery steam generator.

5. Smaller unit size.

6. Water and air are used as working fluids in combined cycle which are available, inexpensive and nontoxic.

Solar thermal systems based on distributed fields of the concentrating collectors can also be used as promising technologies in combined cycle. Hence, the extracted energy from solar systems can be integrated with combined cycle plant to enhance the overall efficiency and decrease the already low emissions. But, due to some limitations of using solar energy, the solar system should satisfy the following requirements [3]:

A. Continuous operation during periods of variable insolation of solar energy,

B. Extended operation to non-solar periods such as cloudy days and night times,

C. Availability of power in emergency periods, and

D. Avoidance of potentially harmful transients arising from abrupt changes in insolation.

Based on the previous discussions and the reality of the solar combined cycle power plant, a computer program has been developed to formulate the problem where it satisfied a flexibility to change input data and also some design conditions. The calculations are based on the effect due to using of the solar energy and the gas turbine wasted energy on the whole thermal efficiency of the plant s' components.

\section{DESCRIPTION OF THE PROPOSED POWER PLANT}

The proposed plant is mainly composed of three units including: solar field, gas turbine unit and steam turbine unit as seen in Fig.1. Solar field consists of a number (M) of rows of the concentrating collectors. These collectors are a cylindrical type with an aperture area of $3 \mathrm{~m}^{2}$ for each one. Each row contains a number $(\mathrm{N})$ of the collectors in series connection where the working fluid is assumed to be distributed uniformly through the rows. The drop in efficiency due to the series connection of the concentrators is considered in the calculations. The heating fluid used in the solar concentrators is Therminol VP1, which is similar to that used in SEGs plants in California [4].

The gas turbine unit consists of a compressor, combustion chamber where the fuel is burned with the air which results the maximum combustion temperature in the cycle. The products of the combustion are expanded adiabatically in the turbine where a part of the developed work is used to drive the compressor (compressor turbine), while the other part is the output from the unit (power turbine). Actual combustion processes and variable specific heats for the compression and expansion processes are considered in the calculations. An isentropic efficiency of $87 \%$ is assumed for the air compressor and the gas turbine in the gas cycle. 


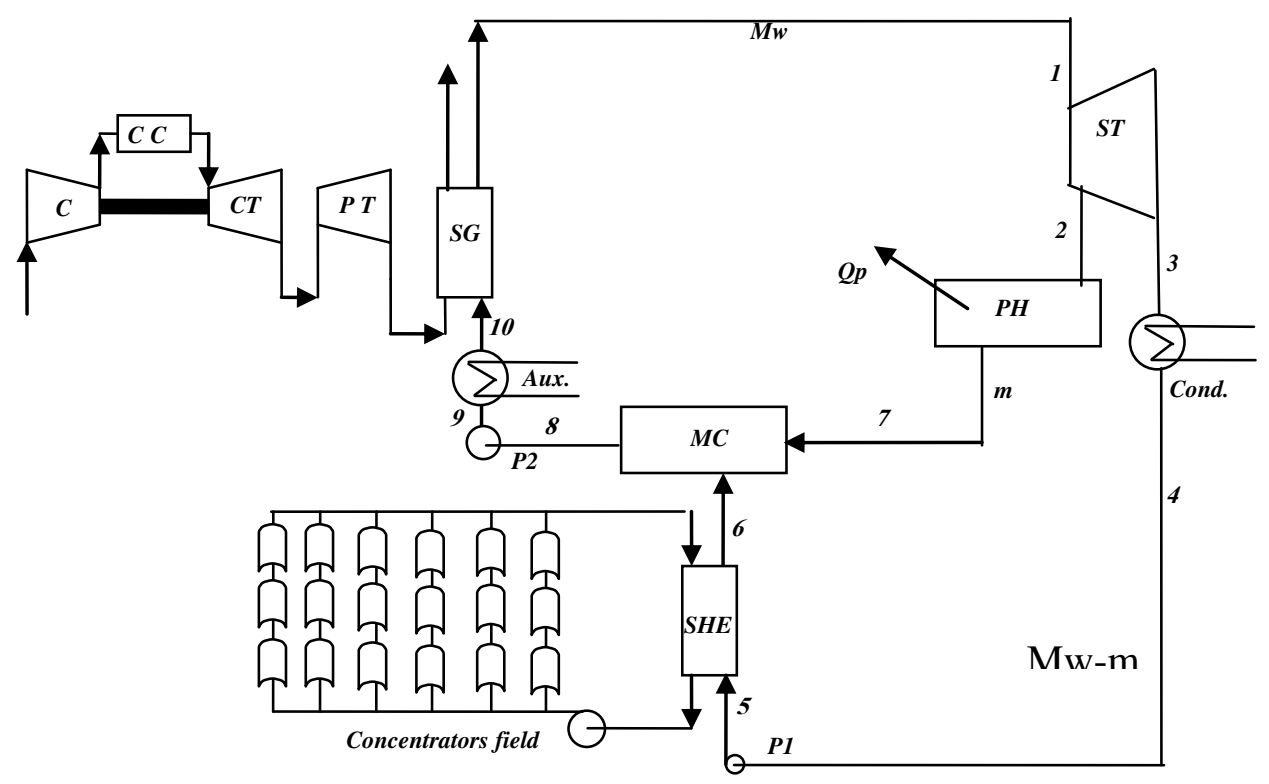

Figure (1). Schematic of the main components of the proposed solar integrated combined cycle power plant

C: compressor, CC: combustion chamber, CT: compressor turbine, PT: power turbine, SHE: solar heat exchanger, ST: steam turbine, PH: process heating, cond.: condenser, SG: steam generator, MC: mixing chamber, Aux: auxiliary heater.

Steam turbine unit is working with Rankine cycle with high pressure of 90 bars while the condenser pressure is fixed at $10 \mathrm{Kpa}$. The extracted steam for heating process is condensed and mixed in mixing chamber with the coming hot water from the solar heat exchanger as seen in the figure. However, in order to assure a steady power generating from the steam turbine, an auxiliary heating system is added in order to raise the temperature of water coming from the mixing chamber up to saturated temperature corresponding to the pressure of the steam generator. This occurred at times of less or absence of solar radiation. Then, the steam generator is used to saturate and superheat steam from saturated liquid to the final state which is a superheating at inlet to the steam turbine. An isentropic efficiency of $87 \%$ for the steam turbine is considered in the calculations.

\section{MATHEMATICAL MODELING}

Each component of the integrated solar combined cycle power plant is treated separately and their models are developed in detail in the following sections.

\section{Solar Concentrating Collector}

The simulation of the solar concentrator is carried out on the basis of the data input to the model as well as the given values for the collector parameters. The calculated 
parameters for the concentrator included: heat losses factor $\left(\mathrm{U}_{\mathrm{L}}\right)$, collector efficiency factor $\left(\mathrm{F}^{\prime}\right)$, and heat removal factor $\left(\mathrm{F}_{\mathrm{R}}\right)$.

Thus, the absorbed heat from the solar concentrator can be expressed by [5]:

$$
Q_{u}=F_{R} A_{a}\left[S-\frac{A_{a b}}{A_{a}} U_{L}\left(T_{f i}-T_{a}\right]\right.
$$

Where:

$$
\begin{gathered}
F_{R}=\frac{m C_{p}}{A_{c} U_{L}}\left[1-\exp \left(-\frac{A_{c} U_{L} F^{\prime}}{m C_{p}}\right)\right] \\
F^{\prime}=\frac{1 / U_{L}}{\frac{1}{U_{L}}+\frac{D_{o}}{h_{f i} D_{i}}+\left(\frac{D_{o}}{2 K} \ln \frac{D_{o}}{D_{i}}\right)}
\end{gathered}
$$

A semi-empirical expression for the overall heat loss coefficient $U_{L}$ for the solar concentrator has been developed $[6,7]$ following the basic procedure of Hottel and Woertz [8]. This expression was modified by Mullick and Nanda [9] and given by:

$$
U_{L}=\left[\begin{array}{l}
\frac{1}{C\left(T_{a b}-T_{c}\right)^{0.25}+\frac{\sigma\left(T_{a b}^{2}+T_{c}^{2}\right)\left(T_{a b}+T_{c}\right)}{1 / \varepsilon_{a b}+\left(D_{a b} / D_{c}\right)\left(1 / \varepsilon_{c}-1\right)}}+\left(\frac{D_{a b}}{D_{c}}\right) \frac{1}{h_{w}+\sigma \varepsilon_{c}\left(T_{c}^{2}+T_{a}^{2}\right)\left(T_{c}+T_{a}\right)}+ \\
\left(\frac{D_{a b}}{D_{c}}\right) \frac{t_{c}}{K_{c}}
\end{array}\right]^{-1}
$$

Where the constant ( C ) in Eq. (4) is given by:

$$
C=\frac{17.74}{\left(T_{a b}+T_{c}\right)^{0.4} \cdot D_{a b} \cdot\left(D_{a b}^{-0.75}+D_{c}^{-0.75}\right)}
$$

The cover temperature in Eq. (4) as a function of the absorbed temperature with a maximum error of $2 \%$ was developed and given by [9]:

$$
T_{c}=T_{a}+0.163\left(D_{a b} / D_{c}\right)^{0.4} \cdot h_{w}^{-0.67}\left[2-3 \varepsilon_{a b}+\left(1+3 \varepsilon_{a b}\right) T_{a b} / 100\right]\left(T_{c}-T_{a}\right) .
$$

Hence, the simulation procedure starts by assuming an approximate value for the absorber temperature $\left(\mathrm{T}_{\mathrm{ab}}\right)$. Based on the assumed temperature with the other given design and ambient data, collector parameters $\left(\mathrm{U}_{\mathrm{L}}, \mathrm{F}\right.$, and $\left.\mathrm{F}_{\mathrm{R}}\right)$ can be calculated, where they are used to calculate the useful heat from the concentrator. Then, an iterative procedure to check the absorbed temperature was performed by the following relation [10]:

$$
T_{a b}=T_{f i}+\frac{Q_{u} / A_{a}}{\left(A_{a b} / A_{a}\right) F_{R} U_{L}}\left(1-F_{R}\right)
$$


The iterative procedure is continued until an acceptable convergence for the concentrator parameters is reached.

However, for collector modules in series connection, the increase of the inlet temperature along the connection line causes a decrease in efficiency. Consequently, for a combination of $(\mathrm{N})$ identical collectors, the average parameters are given by the following relation [11]:

$$
\begin{gathered}
F_{R}(\tau \alpha)=F_{R 1}(\tau \alpha)_{1}\left[\frac{1-(1-K)^{N}}{N K}\right] \\
F_{R} U_{L}=F_{R 1} U_{L 1}\left[\frac{1-(1-K)^{N}}{N K}\right] \\
K=\frac{A_{2} F_{R 2} U_{L 2}}{m C_{P}}
\end{gathered}
$$

Where $F_{R 1} U_{L 1}$ and $F_{R 2} U_{L 2}$ are the parameters for the first and second collector, respectively. Finally, the efficiency of the solar concentrator is expressed by:

$$
\eta_{c}=\frac{Q_{u}}{A_{a} I}=(\tau \alpha)_{e}-\frac{F_{R} U_{L}\left(T_{f i}-T_{a}\right)}{I}
$$

Where $\mathrm{A}_{\mathrm{a}}$ represents the aperture area of the solar concentrator.

\section{Simulation of the Gas Turbine}

The thermal processes through the gas turbine unit include a compression process through the compressor, combustion process through the combustion chamber, and finally expansion process through the gas turbine. The air temperature after the compressor is calculated on the basis a variable specific heat. This requires calculating the relative pressures across the compressor as a function of the compressor pressure ratio $\left(\mathrm{P}_{2} / \mathrm{P}_{1}\right)$, which is given by [2]:

$$
\begin{gathered}
\operatorname{Pr}=\exp \left(\frac{\bar{S}_{T}}{\bar{R}}\right) \\
\frac{P_{2}}{P_{1}}=\frac{\operatorname{Pr}_{2}}{\operatorname{Pr}_{1}}
\end{gathered}
$$

Thus, the exit temperature of the compressor as a function of $\mathrm{Pr}_{2}$ is determined (Table A.1, in Ref. 2) where it is used to calculate the enthalpy of air with variable specific heats by the following relation:

$$
\bar{h}_{T}=\bar{R} T\left(a_{1}+\frac{a_{2} T}{2}+\frac{a_{3} T^{2}}{3}+\frac{a_{4} T^{3}}{4}+\frac{a_{5} T^{4}}{5}+\frac{a_{6}}{T}\right)
$$

Where the constants $a_{l}-\mathrm{a}_{6}$ are given in the same reference.

Applying combustion equation for one mole of octane $\left(\mathrm{C}_{8} \mathrm{H}_{18}\right)$ which is used in the present case with dry air yields [2]: 


$$
\mathrm{C}_{8} \mathrm{H}_{18}+\mathrm{X} \text { D.A } \rightarrow 8 \mathrm{CO}_{2}+9 \mathrm{H}_{2} \mathrm{O}+\mathrm{X} \text { D.A }-12.5 \mathrm{O}_{2}
$$

Where $X$ is the total number of moles of dry air supplied per one mole of fuel. Accordingly, for adiabatic combustion, the enthalpy of reactants in Eq. (15)) is equal to that for the products where the products temperature is calculated by trial and error. Finally, the products of combustion are expanded through the gas turbine giving the power needs to drive the compressor while the remaining part is the developed power output from the turbine.

\section{Simulation of the Steam Turbine}

The main states of the steam in Rankine cycle may be saturated liquid, wet steam or superheated steam, Fig. (1). Also, the main calculated properties of steam included, entropy and enthalpy due to the necessity through the calculations. The net power and the input heat for the steam turbine can be expressed by:

$$
\begin{gathered}
W_{n e t}=M_{w}\left(h_{1}-h_{2}\right)+\left(M_{w}-m\right)\left(h_{2}-h_{3}\right) \\
Q_{p}=m\left(h_{2}-h_{7}\right) \\
Q_{\text {in }}=Q_{\text {solar }}+Q_{\text {aux }}+Q_{s g} \\
Q_{\text {solar }}=\left(M_{w}-m\right)\left(h_{6}-h_{5}\right) \\
Q_{\text {aux }}=M_{w}\left(h_{10}-h_{9}\right) \\
Q_{s g}=M_{w}\left(h_{1}-h_{10}\right)
\end{gathered}
$$

Hence, for Co-generation cycle, the performance of the steam turbine is expressed by utilization factor (instead of efficiency) which is defined by the following relation [1]:

$$
E=\frac{W_{n e t}+Q_{p}}{Q_{i n}}
$$

The states of the main points in Rankine cycle can be defined from the following procedure: The inlet condition of steam turbine i.e. point (1), is obtained from an energy balance to the steam generator as a function of temperature of exhaust gases from gas turbine. Isentropic expansion from $\mathrm{P}_{1}$ to $\mathrm{P}_{3}$ can define the state of point (3). State of point (2) is defined at the extraction pressure, $\mathrm{P}_{2}$. States (4) and (5) are defined on basis of condenser pressure and the work of pump. State (6) is known from an energy balance of solar heat exchanger while state (7) is saturated liquid at $P_{2}$. Point (8) is known from an energy balance of mixing chamber. Point (10) is known by saturated liquid at $\mathrm{P}_{1}$ to assure constant conditions to the steam turbine. Also, through the simulation procedure, the properties of steam are given by Bejan [12] as:

$$
\begin{gathered}
h_{f}=C_{p w} t \\
h_{f g}(T)=\lambda h_{f g}\left(T_{o}\right)
\end{gathered}
$$




$$
\begin{gathered}
\lambda=a_{1} t^{0.33}+a_{2} t^{0.79}+a_{3} t^{1.208}+a_{4} t+a_{5} t^{2}+a_{6} t^{3} \\
h_{g}=h_{f}+h_{f g}
\end{gathered}
$$

The constants $a_{1}-a_{6}$ in Eq. (25) for water are given in Ref. (12). The temperature in Eq. (23) in ${ }^{\circ} \mathrm{C}$, while in Eq. (25) it is given in terms of the reduced temperature $\left(T_{r}\right)$ and the critical temperature $\left(T_{c}\right)$ by: $t=\left(T_{c}-T\right) / T_{c}=1-T_{r}, T_{c}=647.27$ $\mathrm{K}$ for water. Also, $h_{f g}\left(T_{o}\right)$ in Eq. (24) is the latent heat at $273.15^{\circ} \mathrm{K}$.

$$
\begin{gathered}
h_{\text {sup }}=h_{g}+C_{p, \text { sup. }}\left(T_{\text {sup. }}-T_{\text {sat }}\right) \\
S_{\text {sup. }}=C_{p w} \ln \left(\frac{T_{\text {sat }}}{273.15}\right)+\frac{h_{f g}}{T_{\text {sat. }}}+C_{p \text {,sup. }} \ln \left(\frac{T_{\text {sup. }}}{T_{\text {sat. }}}\right)
\end{gathered}
$$

Thus, the properties of the different points in Rankine cycle can be calculated using the developed equations. The calculated properties are used to calculate the parameters in Eqs. (16) to (22).

\section{Exergy Analyses for the Main Components of the Combined Cycle Power Plant}

The second law efficiency or exergy analyses are carried out for the main components of the combined cycle in this section. The exergy destruction takes place in components of both, gas and steam cycles beside solar concentrator. The general equation of exergy destruction for a steady flow system can be expressed by $[1,13]$ :

$$
E X D=T o S_{g e n}=T_{O}\left(\sum m_{e} s_{e}+\frac{Q_{\text {out }}}{T_{b, \text { out }}}-\sum m_{i} s_{i}-\frac{Q_{\text {in }}}{T_{b, \text { in }}}\right)
$$

Where $T_{b, \text { out }}$ and $T_{b \text {, in }}$ are the temperatures of the system boundary where heat is transferred out and into of the system, respectively. In other words these temperatures mean the maximum and minimum temperatures of the system. Based on the developed equation, the exergy generated (the exergy destruction is the product of exergy generated by the surrounding temperature $\mathrm{T}_{\mathrm{o}}$ ) for the whole components of the solar combined cycle is given below $[1,13]$ :

\subsection{An Adiabatic Air Compressor \& Gas Turbine}

$$
S_{g e n}=m\left(s_{e}-s_{i}\right)=m\left(C_{p} \ln \frac{T_{e}}{T_{i}}-R \ln \frac{P_{e}}{P_{i}}\right)
$$

Where the mass flow rate $(m)$ in Eq. (30), represents $\left(m_{a}\right)$ in the compressor while it is $\left(m_{f}+m_{a}\right)$ in the gas turbine, respectively.

\subsection{An Adiabatic Combustion Chamber}

$$
S_{\text {gen }}=S_{\text {prod }}-S_{\text {react }}=\sum N_{P} S_{P}^{-}-\sum N_{r} S_{r}^{-}
$$


Where the air and product gases are at a total pressure (pressure after compressor) and the entropies in Eq. (31) are to be calculated at the partial pressure of the constituents which is equal to: $P_{i}=y_{i} P_{\text {total }}$, for a constituent $i$ where $y_{i}$ is the mole fraction of the component $i$ in the mixture.

\subsection{An Adiabatic Steam Turbine}

$$
S_{g e n}=m_{s}\left(s_{e}-s_{i}\right)
$$

Where $m_{s}$ is the steam mass flow rate while $s_{e}$ and $s_{i}$ are, the actual entropy at exit and inlet sections of the steam turbine, respectively.

\subsection{Condenser of Rankine Cycle}

$$
S_{g e n}=m_{s}\left(s_{e}-s_{i}+\frac{q_{c w}}{T_{O}}\right)
$$

Where $q_{c w}$ is the rate of heat rejected to the cooling water per $\mathrm{Kg}$ of steam and the sink temperature is assumed to be $T_{o}$.

\subsection{An adiabatic heat exchanger}

For steam generator, solar- Rankine heat exchanger:

$$
S_{g e n}=m_{h}\left(s_{e, h}-s_{i, h}\right)+m_{c}\left(s_{e, c}-s_{i, c}\right)
$$

\subsection{Solar concentrator:}

The entropy generating (irreversible) process through the solar concentrator assuming that the absorbing plate is at a uniform temperature and steady state conditions is given by [14-18]:

$$
S_{\text {gen }, c}=m_{f}\left(S_{f, \text { out }}-S_{f, \text { in }}\right)+\frac{Q_{\text {loss }}}{T_{o}}-\frac{(\tau \alpha)_{e} I}{T_{a b}}
$$

Where it is assumed that the concentrator is working between a maximum temperature $T_{a b}$, and a minimum temperature $T_{o}$.

\section{RESULTS AND DISCUSSIONS}

The simulation results of the main parameters affecting the performance of the integrated solar combined cycle power plant are presented in this section. Solutions of the governing equations were generated using the following input data for the solar field and gas turbine: $\mathrm{M}_{\mathrm{w}}=1 \mathrm{~kg} / \mathrm{s}, \mathrm{CPR}=14, \mathrm{M}=30, \mathrm{~N}=30, \mathrm{~A}_{\mathrm{c}}=3 \mathrm{~m}^{2}$, percentage of excess air $=200 \%$.

Figure (2) shows the concentrator efficiency versus the mass ratio (MR) at different values of solar radiation. The presented efficiency in the figure is based on a series connection for the solar concentrators in one row as discussed previously. Also, the mass ratio (MR) means the ratio of the mass of working fluid in the solar loop to the mass of water in the Rankine cycle. It is seen from the figure that the efficiency increases as MR increases due to the decrease of the thermal losses which occurred at the higher mass flow rate through the solar field. Maximum efficiency of about $54 \%$ is achieved in the figure. Looking at the variation of the incident solar radiation, it is seen 
that the higher efficiency curve occurred at the higher value of the incident solar radiation as seen. This is interpreted by the higher increase of the incident solar radiation which is meeting by small increase in the inlet fluid temperature; see Eq. (11) where there is no energy storage. So, the figure shows that the variation of incident solar radiation represents a dominant influence in the concentrator efficiency as seen in the figure.

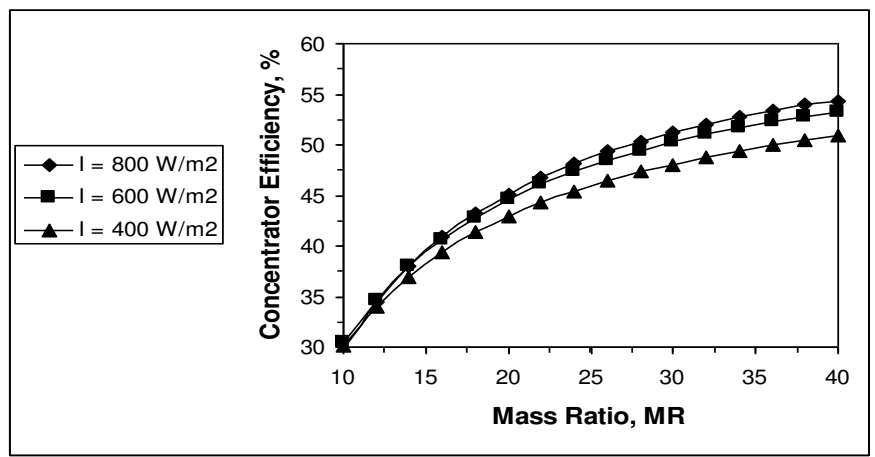

Figure (2). Concentrator efficiency versus mass ratio (MR) at different values of incident solar radiation.

Figure (3) shows the solar contribution factor versus the mass ratio, MR at different values of solar radiation. The solar contribution factor is defined as the ratio of the amount of heat provided by the solar field to the total amount of heat supplied to the steam cycle i.e. $\mathrm{Q}_{\text {solar }} / \mathrm{Q}_{\text {in }}$. It is shown from the figure that the solar contribution increases as the mass ratio increases due to the enhancement of the concentrator efficiency which occurred at the higher values of MR. Also, the solar contribution increases with increase of the solar radiation which seem to be logically. Maximum contribution of about $27 \%$ is attained at MR $=36$ and $\mathrm{I}=800 \mathrm{~W} / \mathrm{m}^{2}$ while the corresponding minimum value is $13 \%$ at the same MR, but with $\mathrm{I}=400 \mathrm{~W} / \mathrm{m}^{2}$. Other factors such as, gas turbine efficiency $(42 \%)$, utilization factor of steam turbine (43 $\%$ ), exhaust gases contribution (63\%), auxiliary contribution (10\%) are resulted from the simulation under these conditions.

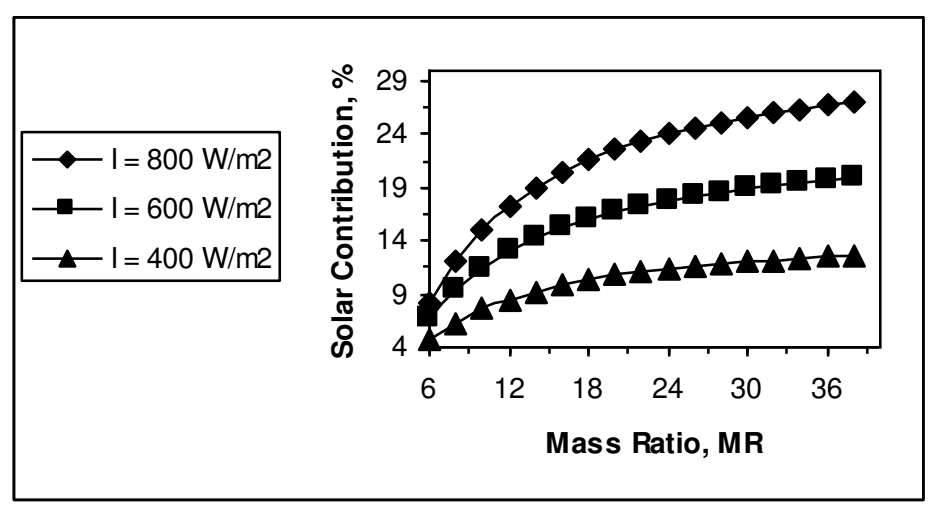

Figure (3). Solar contribution factor versus mass ratio (MR) at different values of incident solar radiation. 
The exergy destruction in the concentrator field at incident solar radiation $(\mathrm{I}=$ $800 \mathrm{~W} / \mathrm{m}^{2}$ ) versus MR with different surrounding temperature (To), is presented in Fig. (4). As seen, the value of exergy destruction decreases as MR increases referring to the decrease of thermal losses corresponding to the higher value of MR. Also, as the surrounding temperature increases, the exergy destruction decreases as seen in the figure. Maximum exergy destruction equals about $33 \%$ from the incident radiation occurred at minimum MR and lower surrounding temperature as seen in Fig. 4.

The concentrator efficiency and solar contribution versus the number of concentrators i.e. area of the concentrators are shown in Figs. (5) and (6), respectively. From Fig. (5), it can be seen that the efficiency of the concentrator decreases as the number of concentrators increases due to the increase of the thermal losses resulting from the increase of the inlet fluid temperature in series connection. Also, the solar contribution increases with the increase of the number $(\mathrm{N})$ due to the increase of the input energy to the system as seen in Fig. (6). However, the increase of the number of concentrators in series connection is needed only to increase the level of the temperature in the cycle but it is limited also by the corresponding decrease in the efficiency in this case.

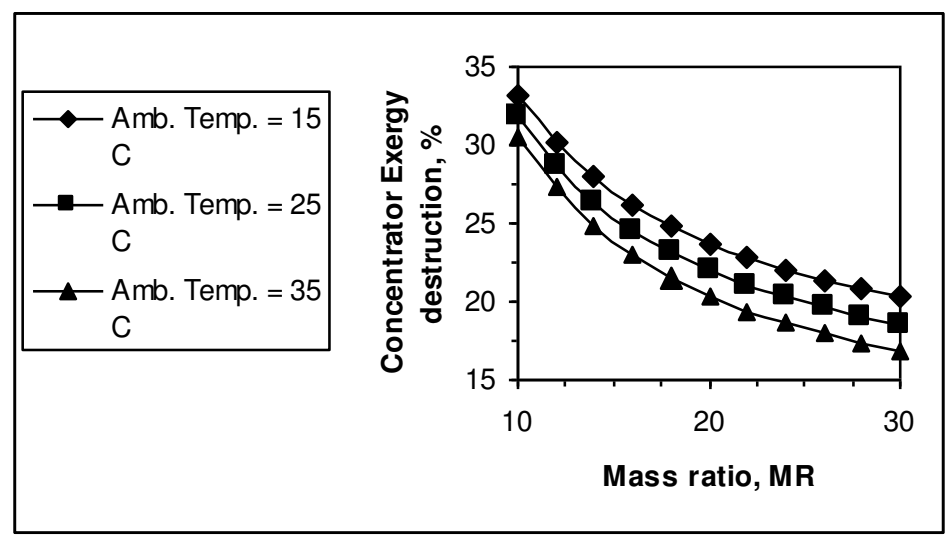

Figure (4). Exergy destruction of the solar concentrator at different surrounding temperatures.

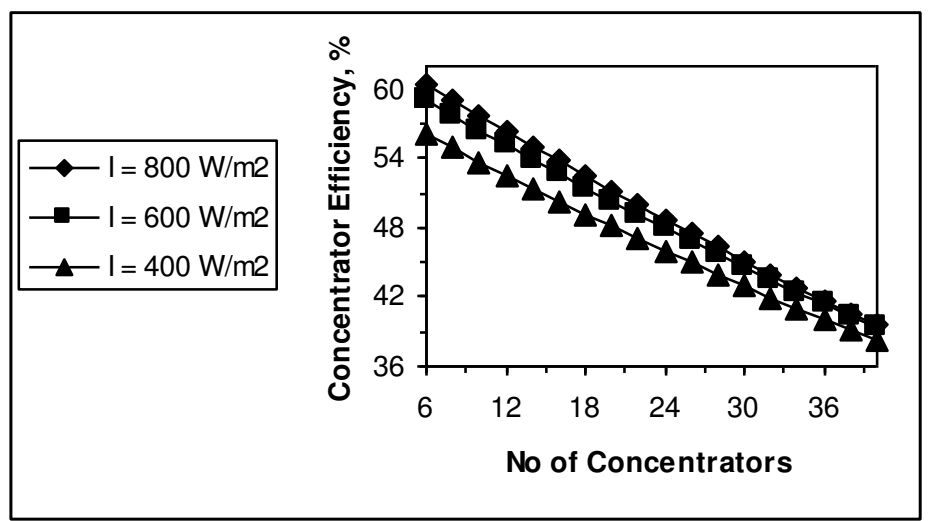

Figure (5). Concentrator efficiency versus number of concentrators at different values of incident solar radiation. 


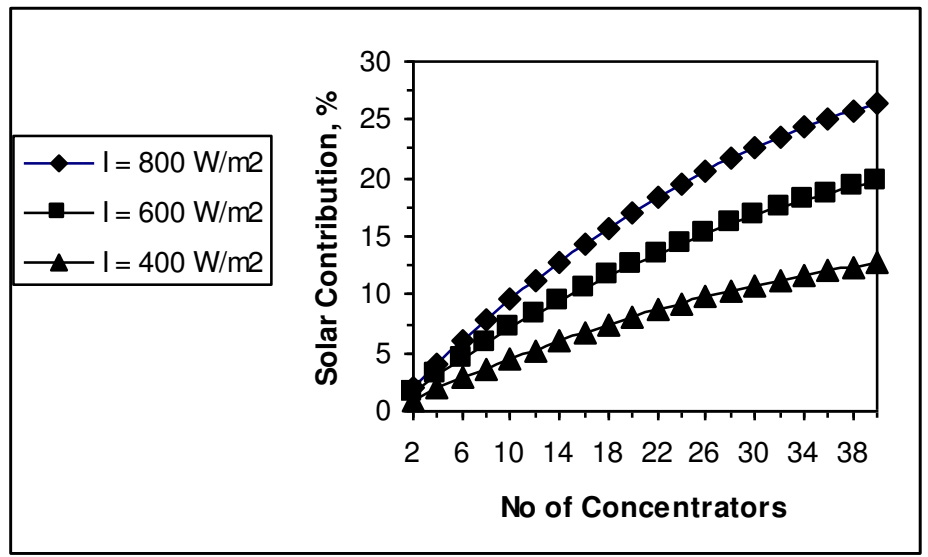

Figure (6). Solar contribution factor versus number of concentrators at different values of incident solar radiation.

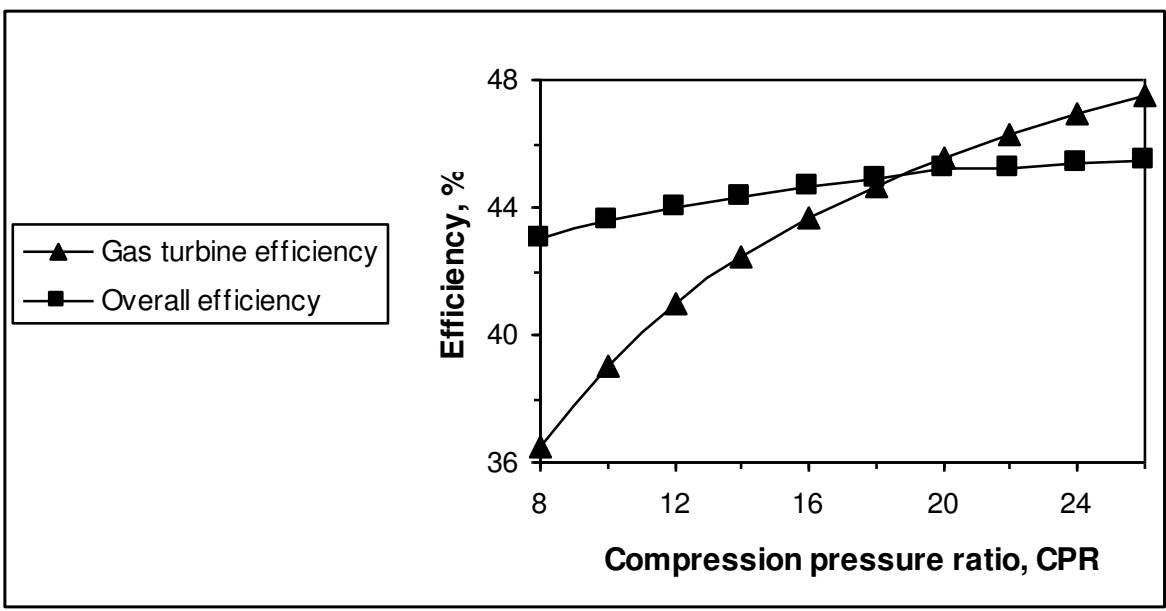

Figure (7). Gas turbine efficiency and overall efficiency versus compression pressure ratio, CPR.

Figure (7) presents the gas turbine efficiency versus CPR in case of burning one kmole of octane $\left(\mathrm{C}_{8} \mathrm{H}_{18}\right)$ with excess air ratio of $200 \%$ and ambient temperature of $298{ }^{\circ} \mathrm{K}$. The overall efficiency is presented also in the figure. As seen in Fig. (7), the gas turbine efficiency increases as CPR increases due to the higher output of the turbine which occurred at the higher combustion temperature at the end of combustion process. But, this temperature is limited also by the metallurgical conditions that the turbine blades can withstand. The trend of efficiency increasing with increasing of CPR is agreed with the calculated values using the air standard cycle of gas turbine (Brayton cycle) in Refs (2 \&13):

$$
\eta_{g t}=1-\left(1 /(C P R)^{\gamma-1 / \gamma}\right)
$$

A simple comparison between the values presented in Fig. (7), and calculated by Eq. (36) yields that the maximum efficiency is nearly $47.5 \%$ at $\mathrm{CPR}=26$ in the figure, while the corresponding value is $60.57 \%$ at the same CPR from Eq. (36). Also, 
the minimum value in the figure is $37 \%$ at $\mathrm{CPR}=8$, while the value calculated from the given equation is $44.79 \%$. The deviation between the values calculated in the paper and that calculated from the given equation is referred to the following considerations in the present model: variable specific heat; actual combustion processes; actual compression and expansion processes. These factors may be interpreted the deviation between the calculated values from the present model and that calculated from the corresponding air standard cycle.

The overall efficiency is presented versus CPR also in Fig. (7), where its value increases as CPR increases due to the increase of power output from gas turbine with higher value of CPR. But, one can find from the figure that there is a convergence between the gas turbine and overall efficiencies up to CPR $=19$ as seen in the figure. This trend is because the overall efficiency is a function of gas turbine efficiency and utilization factor (instead of steam turbine efficiency in Co-generation cycle) where the later decreases as CPR increases, Fig. (8). The decrease of utilization factor with increase of CPR is related to the lower contribution of exhaust gases which occurred with increase of CPR as seen in the figure. Consequently this trend decreases the superheating condition of steam entering the steam turbine giving a lower utilization factor.

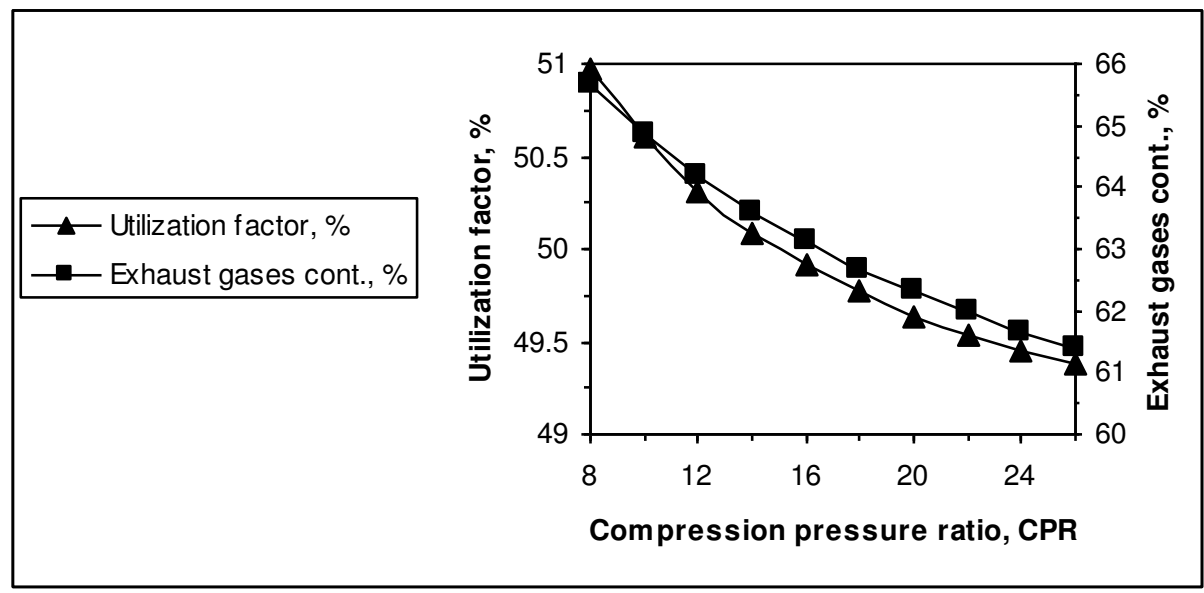

Figure (8). Utilization factor of steam turbine and exhaust gases contribution versus compression pressure ratio, CPR.

Figure (9) presents various temperatures concerning the gas cycle versus CPR. It is clear from the figure that the temperature of air entering the combustion chamber (exit compressor temperature) increases as CPR increases leading to increase the maximum temperature in the cycle. On the other hand, the exit temperature of the products from the turbine decreases as CPR increases due to the lower heat rejected in case of the higher efficiency conditions which occurred at higher CPR, Fig. 7. The maximum temperature in the gas turbine i.e. inlet turbine temperature is presented in the figure where it increases as CPR increases due to the increase of the inlet air temperature as discussed previously. Maximum temperature of $1550{ }^{\circ} \mathrm{K}$ at $\mathrm{CPR}=24$ is attained in the figure. Accordingly, it is important to decrease the maximum temperature for metallurgical reasons via passing an excess air with combustion process. 


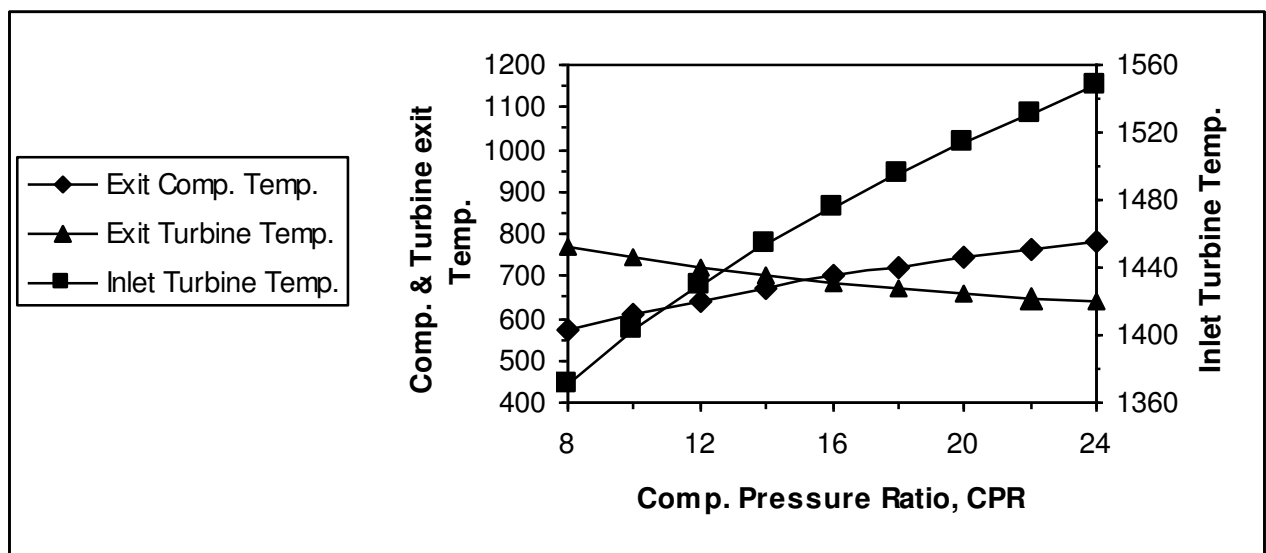

Figure (9). Various temperatures of gas turbine unit versus compression pressure ratio, $\mathrm{CPR}$.

Figure (10) shows the inlet and outlet temperature of gas turbine versus excess air ratio. The figure shows that the inlet temperature to the turbine decreases as excess air ratio increases due to the larger amount of air in combustion products. Of course, the same trend occurred at exit of the turbine where the temperature decreases as seen in the figure. It is important also to select an appropriate value for the maximum temperature in gas turbine cycle. This value may be taken between $1300 \mathrm{~K}$ and $1400 \mathrm{~K}$ which is more closed to the values in different literatures. So, the corresponding excess air ratio corresponding to this range of maximum temperature lies between $200 \%-$ $300 \%$.

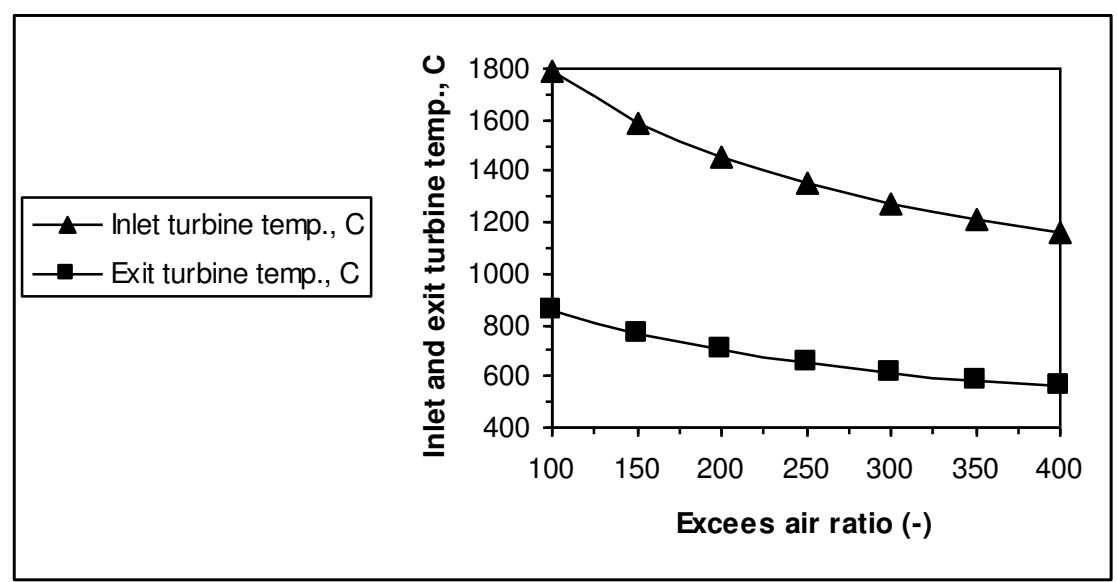

Figure (10). Inlet and outlet gas turbine temperatures versus excess air ratio.

Figure (11) shows the variation of exergy destruction in the main components of gas turbine and steam generator units. The exergy destruction of combustion chamber decreases as CPR increases as seen. This is related to the increase of air temperature entering the combustion chamber compared to the increase of the maximum temperature in the cycle. For example, the air temperature increases by about $56 \mathrm{~K}$ when CPR increases from 12 to 16 , while the maximum temperature increase by about $46 \mathrm{~K}$ only for the same increase of CPR (see Fig.9 and Eq. 31). 


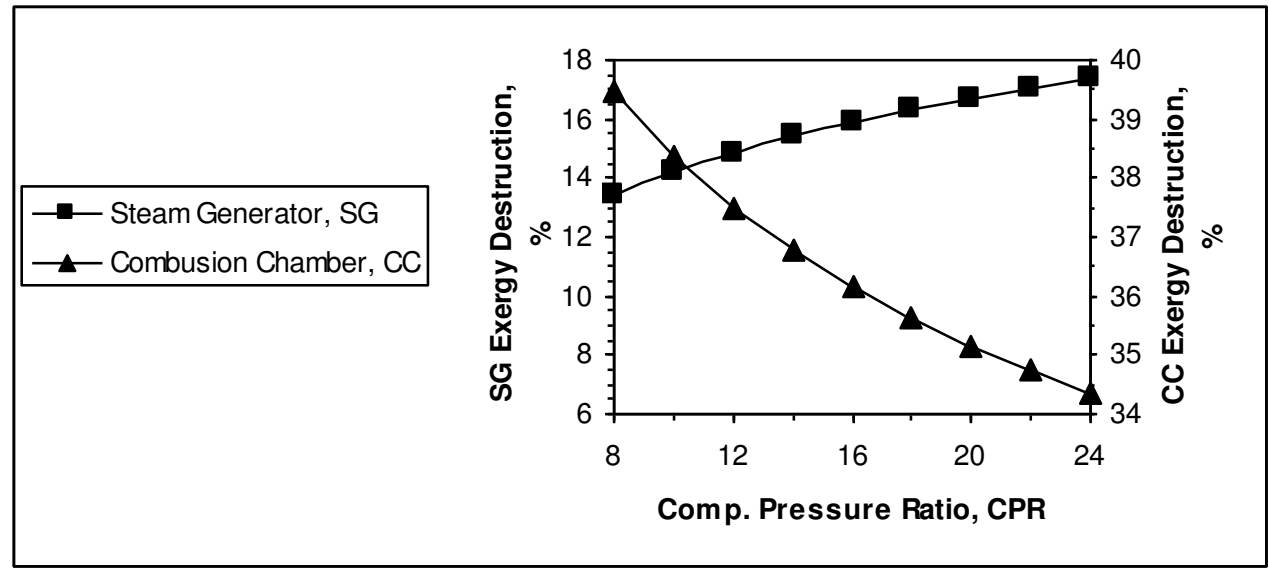

Figure (11). Exergy destruction in combustion chamber and steam generator versus compression pressure ratio, $\mathrm{CPR}$

Maximum exergy destruction with value of $39 \%$ occurred at CPR $=8$ as seen in Fig. (11). However, the exergy destruction for steam generator increases as CPR increases as seen in the figure which is related to the decrease of product temperature entering the steam generator i.e. the entropy change in the product gases side increases with the decrease of the product temperature. Maximum exergy destruction of $17 \%$ from the input heat to gas turbine in steam generator occurred at minimum CPR as seen in Fig. (11). The exergy destruction for the other components of the integrated combined power plant are not presented here where their values are not significant and ranges from $1 \%$ to $5 \%$.

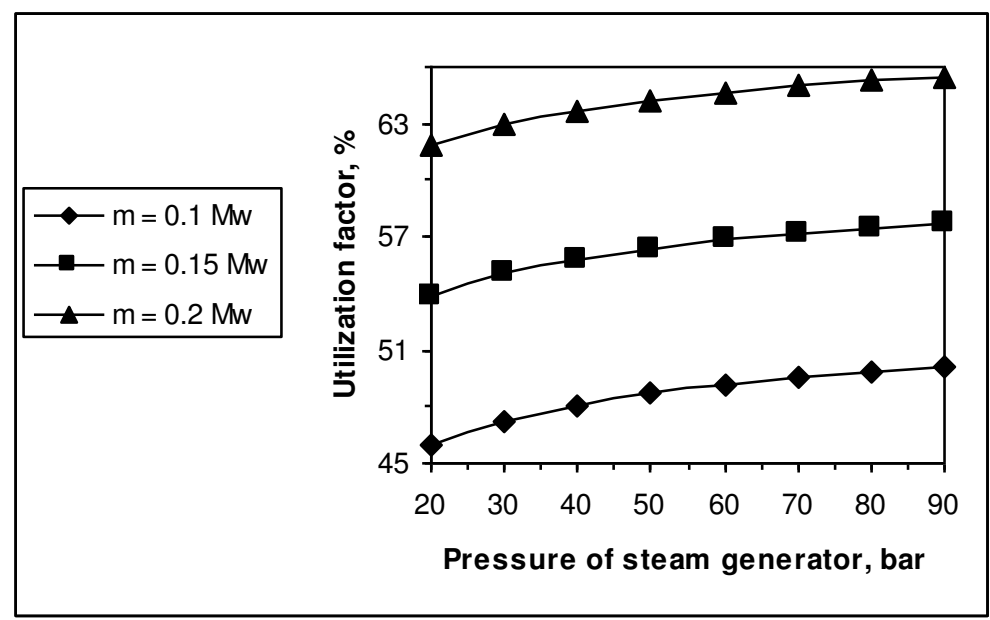

Figure (12). Utilization factor of steam turbine versus steam generator pressure at different values of steam extracted for process heating.

Finally, Fig. (12) presents the utilization factor of steam turbine versus the pressure of steam generator at different amount of steam extracted for heating process. It is seen from the figure that the utilization factor increases as amount of extracted steam increases. This is related to higher utilization of heat from the extracted steam 
from superheating to saturated conditions (state 2 to state 7 in Fig. 1), while it not satisfied in the expansion in the turbine.

\section{CONCLUSIONS}

Based on the developed mathematical model and previous discussions of the simulation results, the following items can be concluded:

- The contribution of solar energy and wasted heat from gas turbine could play an important role in raising the efficiency in solar integrated combined cycle compared to the efficiencies of gas cycle and steam cycle if they are working separately.

- Mass ratio between the water in Rankine cycle and the working fluid in the solar loop is an important performance factor in solar combined cycle. The concentrator efficiency increases as mass ratio increases due to the decrease of heat losses. Also, the exergy destruction of the solar concentrator decreases with increase of the mass ratio due to the lower heat loses.

- Gas turbine efficiency increases with increase of compression pressure ratio, but the exhaust gases contribution decreases with increase of CPR due to the decrease of the heat rejected from the turbine. Maximum exergy destruction in the gas turbine unit occurred in combustion chamber where its value is about $39 \%$ at $\mathrm{CPR}=8$. For other components of the gas and steam turbine units, the exergy destruction ranged from $1 \%$ up to $5 \%$.

- The maximum temperature in gas turbine could be reasonable at excess air ratio ranged from $200 \%$ up $300 \%$.

- The utilization factor of steam turbine increases with increase of the pressure of steam generator as well as the amount of steam extracted for process heating.

\section{REFERENCES}

1. Yunus A. Cengel and Michael A. Boles. "Thermodynamics, an engineering approach", McGraw Hill, $4^{\text {th }}$ edition, 2002.

2. Bathie William W.: "Fundamentals of Gas Turbines", John Wiley \& Sons, Inc, $2^{\text {nd }}$ ed., 1996.

3. Moustafa M. Elsayed, Ibrahim S. Taha, and Jaffar A. Sabbagh: "Design of Solar Thermal Systems". Scientific Puplishing Centre, King Abdulaziz Unversity, Jeddah, $1^{\text {st }}$ ed., 1994.

4. Forristall R., : " Heat transfer analysis and modeling of parabolic trough solar receiver implemented in engineering equation Solver, NREL", Technical reports, USA, 2003.

5. Duffie J. A. and Beckman W. A: "Solar Engineering of Thermal Processes", $2^{\text {nd }}$ ed. , John Wiley \& Sons, Inc. 1991.

6. Mullick S. C. and Nanda S. K.: "Heat loss factor for linear solar concentrators", $J$. Applied Energy 11. 1982.

7. Bhowmik N. C. and Mullick S. C.: "Calculation of tubular absorber heat loss factor", J. Solar Energy, Vol. 35, 1985. 
8. Hottel H.C. and Woertz B. B.: "The performance of flat plate solar collectors", Trans. ASME 64. 1942.

9. Mullick S. C. and Nanda S. K. : "An improved technique for computing heat loss factor of a tubular absorber", J. Solar Energy, Vol. 42, No. 1. 1989.

10. Jui Sheng Hsieh: "Solar Energy Engineering", Prentice-Hall, INC., USA. $1^{\text {st }}$ ed. .1986.

11. Oonk R.D.E. Jones and B. E. Cole Appel: " calculation of N collectors in series from test data on a single collector". J. Solar Energy, 23, 535, 1979.

12. Bejan Adrian: "Advanced Engineering Thermodynamics", John Wiley \& Sons, Inc, $1^{\text {st }}$ ed., 1988.

13. Selwin Rajadurai J.: "Thermodynamics and Thermal Engineering", new age international publishers, New Delhi, $1^{\text {st }}$ ed., 2003.

14. Lovegrove keithl: "Exergy analysis of ammonia- based solar thermo chemical power systems", J. Solar Energy, Vol.66, No.2. 1999.

15. Fujiwara M., " Exergy analysis for the performance of solar collectors". Trans. ASME, J. Solar Energy Engineering, 105, 1983.

16. Suzuki, A., Okamura H., and I. Oshida: "Application of exergy concept to the analysis of optimum operating conditions of solar heat collectors". Trans. ASME, J. Solar Energy Engineering, 109, 1987.

17. Suzuki, A., " A fundamental equation for exergy balance on solar collectors". Trans. ASME, J. Solar Energy Engineering, 106, 1988.

18. Chelghoum D. E. and A. Bejan: " second law analysis of solar collectors with energy storage capability", Trans. ASME, J. Solar Energy Engineering, 107, 1985.

\section{تقيم الاداء و تحليل الاكسرجى لمحطة توليد قدرة تكاملية بالطاقة الشمسية}

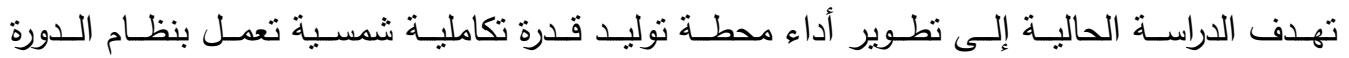

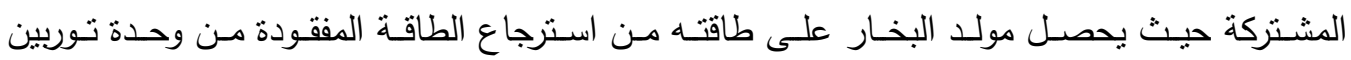

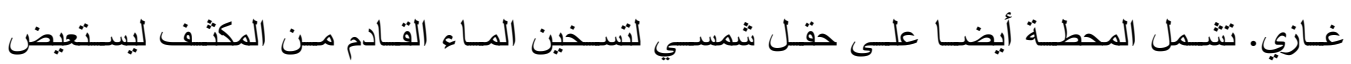

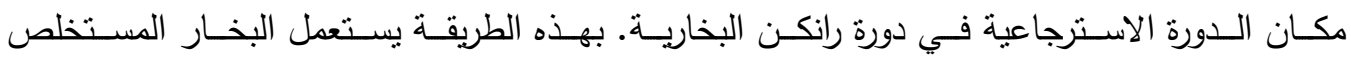

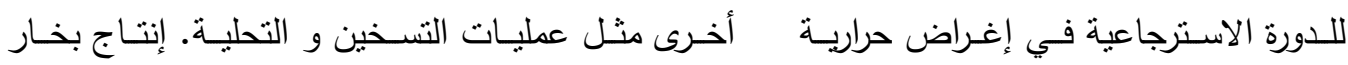

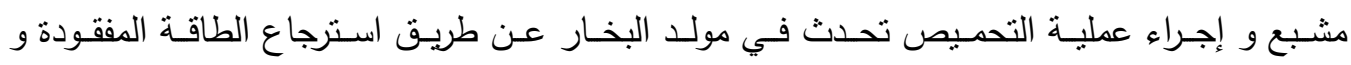

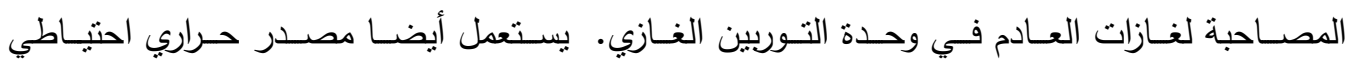

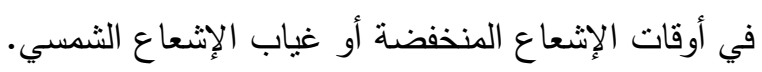

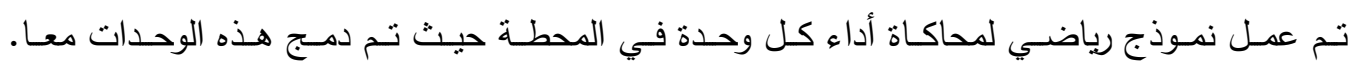

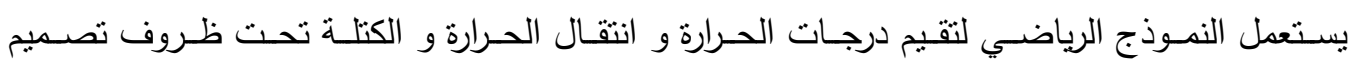

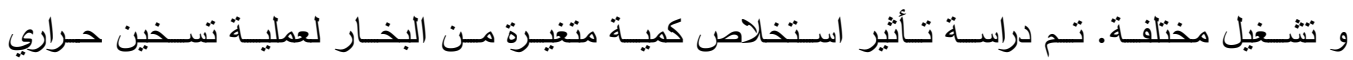

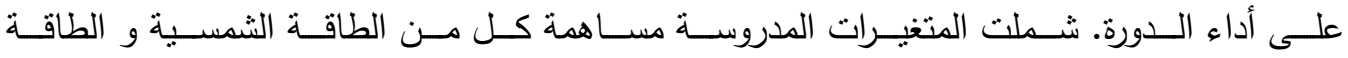




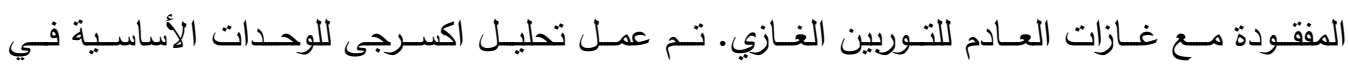

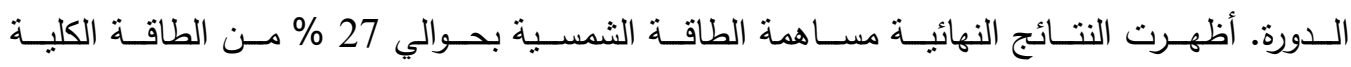

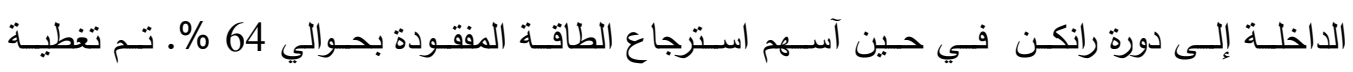

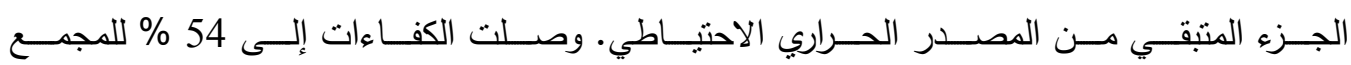

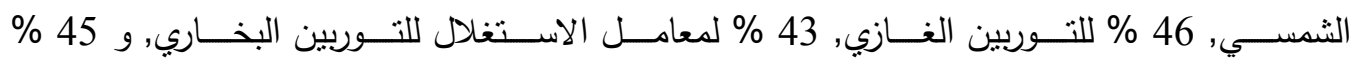

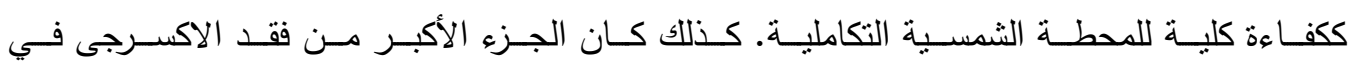

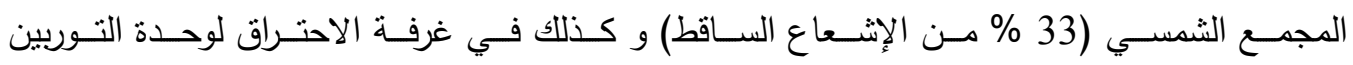

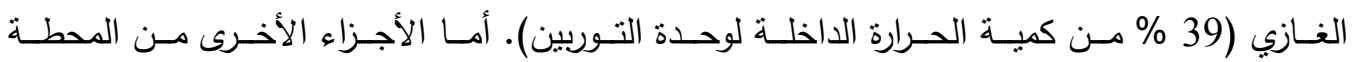
فكانت خسائر الاكسرجى تمثل نسبة ضئيلة بين 1 \% إلى 5 \% 